\title{
Effects of Quality and Price Appeals on Consumers' Internal Reference Prices and Quality Perceptions
}

\author{
Miyuri Shirai \\ Faculty of International Social Sciences, Yokohama National University, Kanagawa, Japan \\ Email: shirai@ynu.ac.jp
}

Received 5 May 2014; revised 2 June 2014; accepted 1 July 2014

Copyright (C) 2014 by author and Scientific Research Publishing Inc.

This work is licensed under the Creative Commons Attribution International License (CC BY). http://creativecommons.org/licenses/by/4.0/

c) (i) Open Access

\begin{abstract}
Marketers frequently appeal to consumers through "high quality" and "low price" cues that are placed together in retail advertisements. We call this type of approach the "high quality and low price" (HQLP) appeal. Few studies have investigated how HQLP appeal influences consumers' evaluations. In this paper, we analyze the effects of HQLP appeal on internal reference prices and quality perceptions in two retailer contexts: expensive and inexpensive stores. The results showed that consumers' evaluations are influenced by both the HQLP appeal and the retailer context. For an expensive store, the appeal generated similar levels of expected price and willingness-to-pay (WTP), higher purchase intention for the expected prices, and lower quality perception. The inexpensive store generated an expected price lower than WTP, higher purchase intention for the expected price, and higher quality perception. Therefore the HQLP appeal works better for an inexpensive store than an expensive store.
\end{abstract}

\section{Keywords}

Advertising Appeal, Internal Reference Price, Quality Perception, Price-Quality Inference

\section{Introduction}

Retailers often simultaneously announce both high quality and low price in their advertisements. For example, Safeway claims "You will find high quality brands at low prices" and H\&M claims "fashion and quality at the best price". This "high quality, low price" (HQLP) appeal indicates that the two semantic cues, "high quality" and "low price", are equivalent. Communicating such an appeal to consumers seems to be rational, since consumers generally have preferences on higher quality products with lower prices. However, the price-quality 
inference theory implies that consumers may not fully accept this appeal because the theory posits that consumers perceive high quality products as also high priced [1] [2]. This means, therefore, that high quality and low price are not equivalent. Hence, how consumers actually evaluate this appeal is unclear. In spite of its popular use, few studies have examined the impact of HQLP appeal on consumer evaluations. One exceptional study, conducted by Shirai [3], investigated whether consumers actually perceive the high quality and low price message from an HQLP appeal. More specifically, Shirai [3] compared the impact of HQLP appeal with an appeal containing the wording "high quality" (HQ-only appeal) and an appeal containing the wording "low price" (LP-only appeal). The results showed that, for quality perception, the HQ-only appeal was highest, the HQLP was second, and the LP-only appeal the least when the product price was high. The HQ-only and HQLP appeals were indifferent and higher than the LP-only appeal when the product price was low. As for price perception, the HQLP and LP-only appeals were indifferent and more favorable than the HQ-only appeal when the product price was high; no effect was observed when the price was low. The implications of these results are that the "high quality" and the "low price" cues included in the HQLP appeal are evaluated separately, and consumers focus more on either one cue or the other, depending on the product price. That is, for high priced products, the "low price" cue is more focused and well-accepted, whereas the "high quality" cue is less meaningful and therefore discounted by the consumer. On the other hand, for a low-priced product, the "high quality" cue is more focused and well-accepted, whereas the "low price" cue is less meaningful and discounted. Shirai [3] conducted an additional study and found that these effects were salient when consumers had weak price-quality schema or a low need-for-cognition.

The present study further investigates consumers' responses to the HQLP appeal, but from a different aspect. This study focuses on the context in which store information is provided, whereas Shirai's study [3] focused on the context in which price information is provided. The main purpose of this study is to investigate the effects of the HQLP appeal in the context of the retailer setting and in the absence of price information. Consumers are found to use store images in constructing price estimates [4] [5]. We adopt retailer types that are familiar to consumers; therefore, consumers should be able to evoke store images easily when given the store information. For consumers' responses, we adopt an internal reference price (IRP) measure. The importance of the IRP in consumers' purchase decisions has reached a consensus among marketing researchers through a considerable amount of empirical evidence. However, few studies have focused on the contextual appeals such as HQLP appeals. Therefore, we take this opportunity to examine the effects of HQLP appeals in two different retail contexts: expensive and inexpensive stores. The following section reviews studies on IRPs in consumer behavior research and presents the hypotheses development.

\section{Theoretical Background}

\subsection{Features of Internal Reference Prices}

Consumers, either consciously or unconsciously, form IRPs with regard to products, either before or during product evaluation tasks. IRP is defined as a criterion recalled from consumers' memories to evaluate the validity or attractiveness of retail prices. If a retail price is lower than the IRP, then the retail price is perceived by the consumer to be less expensive. On the other hand, if a retail price is higher than the IRP, then it is perceived to be expensive. The extent to which a retail price deviates from the consumer's IRP has been considered a major factor influencing consumers' price perceptions [6]. Accordingly, IRP has gained the attention of many consumer behavior researchers because of its importance in manufacturers' and retailers' pricing and promotional decisions. Previous research on IRPs can be classified into two independent branches: the consumer behavior approach, which assesses the effects of external stimuli on IRPs, and the marketing science approach, which concentrates on modeling alternative reference price formulations [7]. Although IRP research originated within the marketing sciences, it has since shifted to consumer behavior research groups. In terms of operationalization, IRPs can be measured in various ways; as a result, these two approaches have adopted completely different IRPs. The consumer behavior groups measure IRPs through questionnaire surveys, generating IRPs such as normal price, expected price, fair price, reservation price, and purchased price. Several studies have attempted to further classify these IRPs [8]-[11]. In contrast, in marketing science, IRPs are estimated through mathematical computer modeling, using consumer panel or point of sale data [12]-[14]. The present study belongs to the former group; therefore, the next section briefly reviews studies from the consumer behavior perspective. 


\subsection{External Stimuli Affecting Internal Reference Prices}

A large number of studies have investigated whether marketing factors affect IRPs. One stream of research has focused on price promotions. Since consumers form IRPs based on the prices observed in the past [6] [15], IRPs are considerably influenced by price promotions, that is, a reduction in retail prices. In general, consumers readily take notice of these reductions, thereby increasing the possibility of remembering the discounted prices and lowering consumers' IRPs. Existing studies demonstrate that IRPs are influenced by price discounts [16], dealing patterns over certain periods [17]-[19], and coupons [20] [21].

Another stream of research focuses on comparative price advertisements, whereby the ads convey an advertised reference price (ARP) such as the regular price or manufacturer's suggested price, in addition to a discounted retail price. The ARP suggests that a deal is being offered [22]. IRPs were found to be influenced by the ARP level [23]-[25], consistency and distinctiveness of the ads [26], and expressions used in the ads [27] [28].

A few studies analyzed the relationship between IRP and retailer context. Thaler [5] demonstrated that consumers' IRPs for a bottle of beer was higher for a fancy resort hotel than a small run-down grocery store. Similarly, Bolton et al. [4] showed that a department store generated a higher IRP than a discount store for clothing and a convenience store generated a higher IRP than a grocery store for a pint of ice cream. These results imply that consumers spontaneously acknowledge a store's price image and use that knowledge in forming an IRP.

This study examines the effects of contextual appeals on IRPs that have not been fully analyzed up until now. In particular, we analyze the effects of HQLP appeals on consumers' IRPs in comparison with the HQ-only and LP-only appeals. Shirai [3] demonstrated that price and quality perception are influenced by these appeals, and on the basis of those results we can predict that IRPs are influenced by the appeals, since IRPs are associated with price [13] and quality perception [29]. We also adopt the retailer context as an additional factor, as IRPs are found to be influenced by the context. Accordingly, we examine an interactive effect of contextual appeal type and retailer context on consumers' IRPs.

\subsection{Hypotheses}

We adopt two types of IRPs: expected price (EP) and willingness-to-pay (WTP). EP is defined as the price consumers expect to pay for a product [17] and WTP is defined as the price consumers are willing to pay for a product [30] [31]. WTP is often defined as a reservation price, which means the maximum price consumers are willing to pay for a product [32]; however, we do not adopt this type of WTP because it is associated only with the upper end of IRPs and is considered as a less general measure for judging retail prices. In addition to these IRPs, we include quality perception in our hypotheses. In a study of comparative price advertisement providing price and product information, Grewal et al. [29] found that IRP and quality perception are positively and highly correlated. Unlike Grewal et al. [29], both quality perception and IRPs are formed by store image in our study; therefore, whether a strong positive relationship appears is uncertain. Therefore, we examine this relationship and set the first hypothesis as follows:

H1: There is a positive relationship between EP and quality perception, and between WTP and quality perception.

Next, we set a hypothesis regarding the effects of store type. Following the findings of a previous study, where expensive stores generated estimates of actual price and fair price higher than inexpensive stores [4], we expect to observe higher EP, WTP, and quality perception for an expensive store than an inexpensive store. Expensive stores generally offer better services, more pleasant in-store environments, and better merchandise than inexpensive stores. Hence, these predictions are considered adequate and we present the following:

H2: EP, WTP, and quality perception will be higher in the context of an expensive store than the context of an inexpensive store.

We now set the hypotheses with regard to interactive effects of contextual appeal type and store type. On the basis of Shirai's study [3], we anticipate the appeal type is also an influential factor in the context of retailer setting; however, its effects are expected to manifest differently depending on store type. First, we discuss effects in the context of an expensive store. We predict that the HQ-only appeal will generate higher EP, WTP, and quality perception than the HQLP and LP-only appeals, since an expensive store generally has an image of high quality and this image matches with the HQ-only appeal fairly well. On the other hand, the HQLP appeal is expected to lower EP, WTP, and quality perception. Shirai [3] argued that consumers seem to focus on the "low price" cue more than the "high quality" cue in this appeal when observing a high priced product. Hence, we 
presume the "low price" cue will be focused more in the context of an expensive store; therefore, it generates lower IRPs. Shirai [3] additionally showed that the HQLP appeal lowered quality perception for a high priced product. Accordingly, quality perception evoked by the HQLP appeal is also expected to be lowered. As for the LP-only appeal, it should generate low EP, WTP, and quality perception. This is an uncommon appeal in an expensive store and should have impacts on consumers' evaluations. We assume that the effects of the LP-only appeal are similar to those of the HQLP appeal in this context. Therefore, we propose the following:

H3a: In the context of expensive store, EP, WTP, and quality perception generated by the HQ-only appeal will be higher than the HQLP appeal and the LP-only appeal. Effects of the HQLP appeal and LP-only appeal will be similar.

In the context of an inexpensive store, we predict that the LP-only appeal will generate lower EP, WTP, and quality perception than the HQLP and HQ-only appeals, since the LP-only appeal matches with its store image fairly well. Shirai [3] argued that consumers focus the "high quality" cue more than the "low price" cue in the HQLP appeal when observing a low-priced product. Hence, we presume the "high quality" cue would be focused more in the context of an inexpensive store; therefore, the HQLP appeal will generate higher IRPs and quality perception. As for the HQ-only appeal, since it is an uncommon cue in an inexpensive store and should have impacts on consumers' evaluation, we assume that the effects of the HQ-only appeal are similar to those of the HQLP appeal in this context. Accordingly, the following relationship is hypothesized:

H3b: In the context of inexpensive store, EP, WTP, and quality perception generated by the LP-only appeal will be lower than the HQLP appeal and the HQ-only appeal. Effects of the HQLP appeal and the HQ-only appeal will be similar.

Finally, we compare two IRPs: EP and WTP. We presume EP is influenced more by retailer context than WTP. Bolton et al. [4] showed that the estimate of actual price was dependent on retailer context. Since their price estimate is very similar to EP by definition, we anticipate EP is also be influenced by retailer context. Also, Ranyard et al. [33] found that the effect of retailer context on WTP was small and influenced more by an estimation of normal price of product. Accordingly, we expect that the retailer context influences EP more than WTP. This means that the variance of EP should be larger than the variance of WTP. Moreover, we predict that EP will be higher than WTP in an expensive store, since consumers usually expect to see higher prices on products. Conversely, in an inexpensive store, consumers usually become price-conscious and expect to see lower prices on products; therefore, we predict EP and WTP will be similar or that EP will be lower than WTP, and the following hypotheses are proposed:

H4a: The variance of EP will be larger than the variance of WTP. This phenomenon is more salient in the context of expensive stores than the context of inexpensive stores.

H4b: EP will be higher than WTP in the context of expensive stores. They will be similar, or EP will be lower than WTP in the context of inexpensive stores.

\section{Study}

\subsection{Design and Stimulus}

A controlled experimental method was designed to test our hypotheses. The experiment design utilized a 3 (appeal type) $\times 2$ (store type) between-subjects array. All experimental materials were contained in booklets. Crossing appeal type with store type resulted in six conditions; therefore, six versions of the experimental booklet were created. The three levels of appeal type were the HQLP appeal, the HQ-only appeal, and the LP-only appeal; the levels of store type were expensive store and inexpensive store. We selected a department store for the expensive store condition and a discount store for the inexpensive store condition.

We selected a polo shirt as the target product category because participants could visualize the product easily, with little variation among brands. These items are sold in both expensive and inexpensive stores, and both males and females can be shoppers of the product. Also, this product was successfully used in a past experimental study [4].

\subsection{Participants and Procedures}

In all, 168 undergraduate students at a major Japanese university participated in this study in exchange for extra credits. Participants were randomly assigned to one of the six experimental conditions via the questionnaires, 
which were randomized. The number of participants in each condition ranged from 27 to 29 .

Questionnaires were administered by paper and pencil in a classroom setting. A scenario approach was adopted and participants were presented a scenario describing the shopping situation in the questionnaire. Alba et al. [34] asserted that not only prices, but also in-store atmosphere and advertisements create price beliefs and these beliefs do not change much once formed. To confirm general images of department stores and discount stores, we ran a pretest $(n=14)$ by using a five-point scale with anchors " $1=$ very expensive" and " 5 = very inexpensive" for price and anchors " 1 = very bad" and " 5 = very good" for quality, in-store atmosphere, and attitude of store clerks. As expected, participants rated department stores higher than discount stores on price $\left(M_{\text {department }}=1.86, M_{\text {discount }}=4.36, t(13)=14.38, p<0.0001\right)$, quality $\left(M_{\text {department }}=4.43, M_{\text {discount }}=2.71, t(13)=\right.$ $6.45, p<0.0001)$, in-store atmosphere $\left(M_{\text {department }}=4.43, M_{\text {discount }}=3.14, t(13)=6.63, p<0.0001\right)$, and attitude of store clerks $\left(M_{\text {department }}=4.71, M_{\text {discount }}=2.93, t(13)=8.33, p<0.0001\right)$. Accordingly, we included information regarding in-store atmospheres and merchandise in scenarios. The following scenarios were used.

Department store: You are now on a trip to a principal city in the region and visiting a locally famous department store to do some shopping. This store provides a feeling of quality. It also offers a pleasant, elegant, and relaxed atmosphere. You notice that this store has an abundant line-up of products and offers more services. While browsing through the shop, you notice a polo shirt on display that is completely to your taste. When you look closely at the polo shirt, you see a tag with the caption, "High quality, low price" and the message "We offer low prices while maintaining high quality". [The tag had a caption "High quality" and the message "We offer high quality" for the HQ-only appeal scenario; the tag had a caption "Low price" and the message "We offer low price" for the LP-only appeal scenario.]

Discount store: You are now on a trip to a principal city in the region and visiting a locally well-known discount store to do some shopping. The in-store environment is like a typical discount store. While browsing through the shop, you notice a polo shirt on display that is completely to your taste. When you look closely at the polo shirt, you see a tag with the caption, "High quality, low price" and the message "We offer low prices while maintaining high quality". [The tag had a caption "High quality" and the message "We offer high quality" for the HQ-only appeal scenario; the tag had a caption "Low price" and the message "We offer low price" for the LP-only appeal scenario.]

Participants were asked to read and imagine the given scenario. Then, they were asked to assess several measures regarding the featured product and respond to other questions. This type of scenario approach is frequently adopted by marketing researchers [4] [5] [33] [34].

\subsection{Measures}

Participants were asked to provide their EP, WTP, and quality perceptions for the polo shirt. We also asked their purchase intentions at the expected price that they had indicated (PI_for_EP). EP was measured with an open-ended question, "How much do you think this store will charge for the polo shirt?" WTP was measured with an open-ended question, "How much are you willing to pay for the shirt?" These measures are used in previous studies [30] [31]. EP and WTP were measured in the Japanese yen, the currency of Japan (JPY). JPY approximately converts to USD1 = JPY100. Quality perception was measured on a 7-point scale, from "very bad" to "very good", and "very unreliable" to "very reliable". Responses were averaged to form a quality perception index ( $r=0.85, p<0.0001)$. PI_for_EP was measured with two questions, "How probable is it that you would purchase this shirt at your expected price?" and "How much would you like to purchase this shirt at your expected price?" Both questions were assessed on a 7-point scale, using "not at all" and "very much" as anchors. Responses were averaged to create a PI_for_EP index ( $r=0.7, p<0.0001)$. Finally, participants were asked how much they liked shopping at department and discount stores respectively using a 7-point scale, with "dislike very much" and "like very much" as anchors.

\subsection{Results}

To test H1, we first conducted correlational analyses. The results showed a positive relationship between EP and quality perception $(r=0.46, p<0.0001)$, and between WTP and quality perception $(r=0.29, p<0.0001)$. Correlational analyses by each store type showed that EP had a positive correlation with quality perception for both stores ( $r=0.38, p<0.001$ for department store; $r=0.32, p<0.01$ for discount store); however, WTP had a positive correlation only for the discount store $(r=0.09$, n.s. for department store; $r=0.25, p<0.05$ for discount 
store). For the department store, quality perception and WTP were not even related. Overall, H1 is supported, but the relationships are not very strong, and EP is associated to quality perception more than WTP. These results imply that constructing processes of EP and WTP are different and quality perception is a more essential element for the process of EP than WTP.

Next, before examining individual analyses of variance (ANOVA) for each variable, we carried out a $3 \times 2$ multivariate ANOVA (MANOVA) involving appeal type and store type as independent variables and the four measures (EP, WTP, quality perception, and PI_for_EP) as dependent variables. This analysis is suggested by Bobinski et al. [35]. The MANOVA revealed overall significant effects of appeal type (Wilk's $\lambda=0.6, F=$ 11.49, $p<0.0001$ ) and store type (Wilk's $\lambda=0.67, F=19.82, p<0.0001$ ), and an interaction effect (Wilk's $\lambda=$ $0.82, F=4.11, p<0.001)$. Table 1 shows the mean and standard deviation results for each condition.

Subsequently, ANOVAs were performed for EP, WTP, and quality perception to test H2, H3a, and H3b, respectively. The results for EP revealed main effects of appeal type $\left(F(2,162)=32.28, p<0.0001 ; M_{\mathrm{HQLP}}=\mathrm{JPY}\right.$ $3829, M_{\text {HQonly }}=$ JPY 6217, $M_{\text {LPonly }}=$ JPY 3019) and store type $\left(F(1,162)=61.75, p<0.0001 ; M_{\text {department }}=\right.$ JPY 5655 versus $M_{\text {discount }}=$ JPY 3036). Note that store type has a larger effect than appeal type. The significant main effect of store type indicates that $\mathrm{H} 2$ is supported for EP. An interactive effect between appeal type and store type $(F(2,162)=7.39, p<0.001)$ is shown in Figure 1 . This figure shows that consumers in the department store are more influenced by the appeal type. A separate ANOVA performed for each store type revealed that the main effect of appeal type was stronger for the department store $(F(2,83)=23.55, p<0.0001)$ than the discount store $(F(2,83)=8.95, p<0.001)$. Follow-up Tukey tests indicated that the HQ-only appeal was highest while the HQLP and LP-only appeals came second for both stores. These results are consistent with H3a. H3b is partially supported since the HQ-only and HQLP appeals did not have similar effects.

WTP showed a marginally significant main effect for appeal type $\left(F(2,162)=2.87, p<0.06 ; M_{\mathrm{HQLP}}=\mathrm{JPY}\right.$ 4398, $M_{\text {HQonly }}=$ JPY 4475, $M_{\text {LPonly }}=$ JPY 3638) and a significant main effect of store type $(F(1,162)=32.84, p$ $<0.0001 ; M_{\text {department }}=$ JPY 5051 versus $M_{\text {discount }}=$ JPY 3298). Again, store type has a larger effect than appeal type. The main effect of store type indicates that H2 is supported for WTP. No significant interactive effect between appeal type and store type was confirmed and a separate ANOVA for each store did not reveal main effects of appeal type. Therefore, H3a and H3b are not supported for WTP. These results also imply that the constructing process differs between EP and WTP. When constructing EP, consumers take account of retailers' appeals to a greater extent than when constructing WTP.

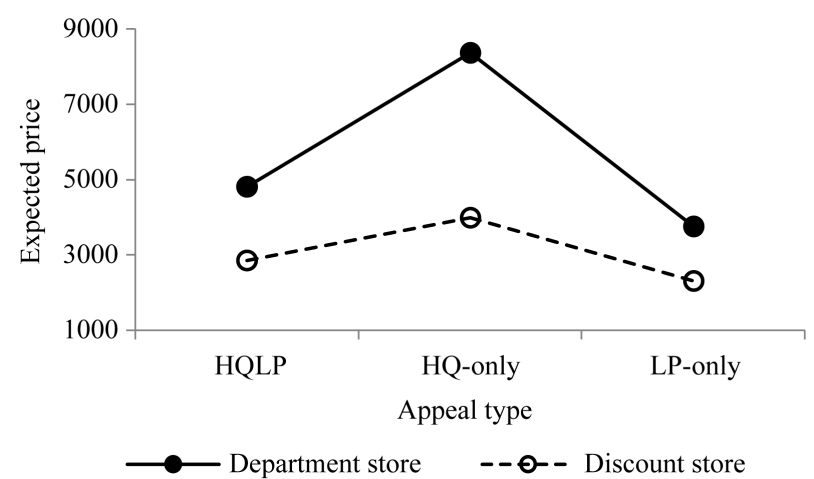

Figure 1. Interactive effect on expected price.

Table 1. Means and standard deviations across conditions.

\begin{tabular}{ccccccccc}
\hline \multirow{2}{*}{$\begin{array}{c}\text { Appeal } \\
\text { type }\end{array}$} & \multicolumn{2}{c}{ EP } & \multicolumn{2}{c}{ WTP } & \multicolumn{2}{c}{ PI_for_EP } & \multicolumn{2}{c}{ Quality perception } \\
\cline { 2 - 8 } & Departmentstore & Discountstore & Departmentstore & Discountstore & Departmentstore & Discountstore & Departmentstore & Discountstore \\
\hline HQLP & $4808(2494)$ & $2851(1232)$ & $5228(2025)$ & $3568(1550)$ & $5.57(1.11)$ & $5.31(0.95)$ & $5.07(1.13)$ & $4.76(0.75)$ \\
HQ-only & $8364(3389)$ & $3990(2104)$ & $5496(2214)$ & $3418(2212)$ & $4.27(1.16)$ & $3.98(1.52)$ & $5.77(1.01)$ & $4.48(1.04)$ \\
LP-only & $3755(1671)$ & $2309(967)$ & $4400(2332)$ & $2903(1326)$ & $4.8(1.47)$ & $5.45(1.20)$ & $5.02(1.34)$ & $3.88(1.14)$ \\
\hline
\end{tabular}

Note: Standard deviations are in parentheses. 
Finally, for quality perceptions, main effects of appeal type $\left(F(2,162)=5.94, p<0.01 ; M_{\mathrm{HQLP}}=4.97, M_{\mathrm{HQonly}}\right.$ $\left.=5.14, M_{\text {LPonly }}=4.44\right)$ and store type $\left(F(1,162)=32.32, p<0.0001 ; M_{\text {department }}=5.32\right.$ vs. $\left.M_{\text {discount }}=4.38\right)$, and a marginal interactive effect $(F(2,162)=2.67, p<0.07$, Figure 2$)$ were revealed. A stronger effect of store type compared with appeal type was again confirmed here. The effect of the store type indicates that H2 is supported for quality perception. A separate ANOVA for each store was significant for both department store $(F(1,162)=$ $3.2, p<0.05)$ and discount store $(F(1,162)=5.94, p<0.01)$. Tukey tests indicate that the HQ-only appeal was highest while the HQLP and LP-only appeals came second for the department store, consistent with H3a. For the discount store, the HQ-only and HQLP appeals were indifferent and higher than the LP-only appeal, consistent with H3b.

H4a compares the standard deviations of EP and WTP: JPY2886.72 for EP and JPY2167.3 for WTP. Bartlett's test for equal variances confirmed that they are significantly different $(F(167)=1.77, p<0.001)$. We then compared the standard deviations of EP and WTP between the two store types. For EP, the results were JPY3257.08 for the department store and JPY1639.94 for the discount store and Bartlett's test confirmed it was larger for the department store than the discount store $(F(83)=36.13, p<0.0001)$. For WTP, the results were JPY2212.92 for the department store and JPY1731.56 for the discount store. Bartlett's test confirmed it was larger for the department store $(F(83)=4.92, p<0.05)$. Apparently, the department store generates larger standard deviations than the discount store for both EP and WTP. These results are consistent with H4a.

Finally, we performed paired $t$ tests between the means of EP and WTP to test H4b. The overall $t$ test showed that EP and WTP were indifferent $(t(167)=0.96$, n.s.). However, $t$ tests conducted for each store type revealed different results. For the department store, EP was marginally higher than WTP $\left(M_{E P}=5654, M_{W T P}=5051 ; t\right.$ (83) $=1.92, p<0.06)$, but for the discount store, EP was marginally lower than WTP $\left(M_{E P}=3036, M_{W T P}=3298 ; t\right.$ $(83)=-1.64, p<0.1)$. We conclude that H4b is supported. Also, we conducted paired $t$ tests for each of six conditions. The results showed that the HQLP appeal generated EP similar to WTP for the department store $(t$ $(28)=-1.22$, n.s.), but generated EP lower than WTP for the discount store $(t(28)=-2.8, p<0.01)$. The HQ-only appeal generated EP higher than WTP for both store types $(t(27)=4.58, p<0.0001$ for department store; $t(26)=1.83, p<0.08$ for discount store). Conversely, the LP-only appeal generated EP lower than WTP for both store types $(t(26)=-1.91, p<0.07$ for department store; $t(27)=-3.07, p<0.01$ for discount store). Effects on EP and WTP apparently differ among the three appeal types.

Lastly, we report results of ANOVA, setting PI_for_EP as a dependent variable. The main effect of appeal type $\left(F(2,162)=17.03, p<0.0001 ; M_{\mathrm{HQLP}}=5.44, M_{\mathrm{HQonly}}=4.13, M_{\mathrm{LPonly}}=5.13\right)$ and a marginal interactive effect $(F(2,162)=2.55, p<0.08$, Figure 3$)$ were observed, but no main effect of store type was observed. A separate ANOVA conducted for each store type revealed that the main effect of appeal type was stronger for the discount store $(F(2,83)=11.78, p<0.0001)$ than the department store $(F(2,83)=7.81, p<0.001)$. Tukey tests indicated that, for the department store, the HQLP was highest, whereas the HQ-only and LP-only appeals came second. The HQLP and LP-only appeals were indifferent and higher than the HQ-only cue for the discount store.

\subsection{Discussion}

Taken together, the effects of the HQLP appeal differ between the two store types, as expected. For the department store, the appeal evokes EP close to WTP, resulting in the highest PI_for_EP among the three appeals.

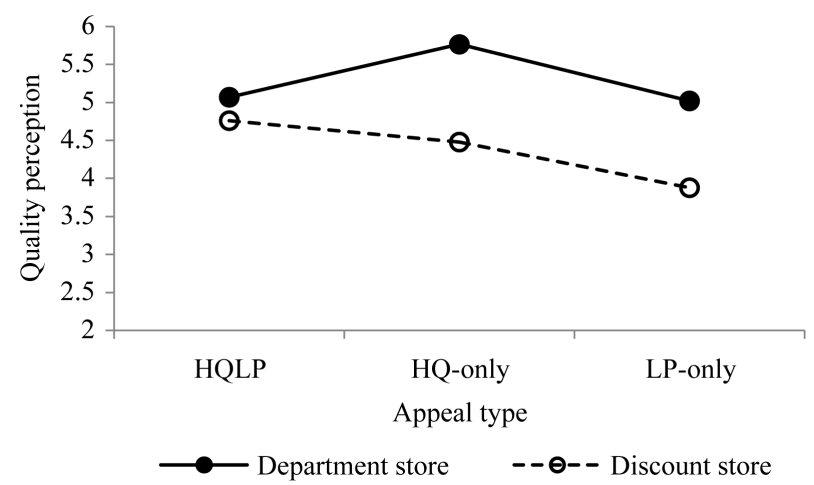

Figure 2. Interactive effect on quality perception. 

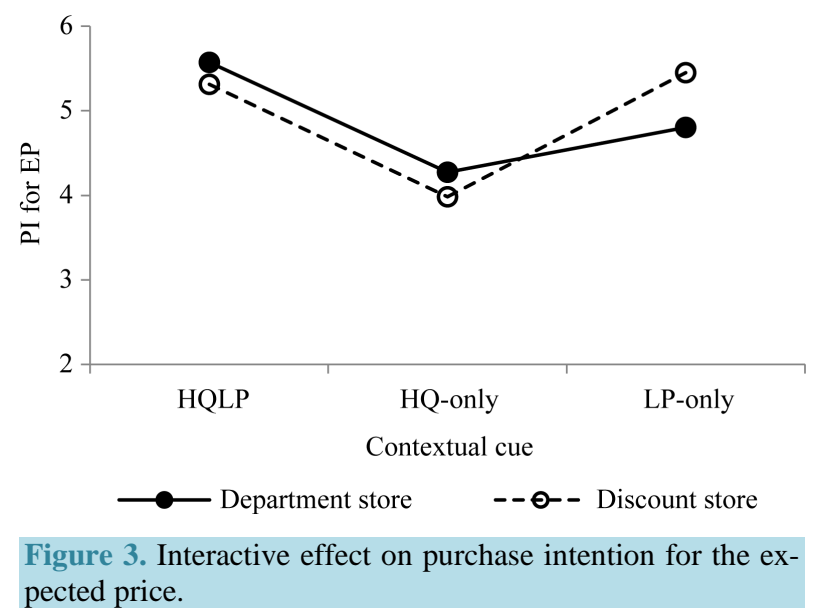

However, it also evokes quality perception lower than the HQ-only appeal at the same time. For the discount store, the HQLP appeal generates EP lower than WTP, resulting in PI_for_EP as high as the LP-only appeal, and quality perception as high as for the HQ-only appeal. Hence, the HQLP appeal works for both store types, but better for the discount store.

The HQ-only appeal generates EP higher than WTP, resulting in lower PI_for_EP for both stores. This PI_ for_EP of HQ-only appeal was lowest for the discount store so that the HQ-only appeal may not be appropriate in the context of the discount store. We note that having high EP may lead to better positive price perception upon observing a retail price, so consumers may generate high purchase intention after all; however, this works better for the department store than the discount store, since the former is accompanied by a higher quality perception. Conversely, the LP-only appeal generates EP lower than WTP, resulting in higher PI_for_EP. This is more salient for the discount store. Therefore, the LP-only appeal is well-accepted in the context of a discount store.

Additionally, we analyzed a possible moderating effect of liking for each store. ANOVA results indicated that liking for the department store did not affect responses, but liking for the discount store interacted with appeal type to influence PI_for_EP $(F(2,157)=3.09, p<0.05)$ and quality perceptions $(F(2,157)=3.83, p<0.01)$. When the HQ-only appeal or LP-only appeal was present, consumers who liked the discount store evaluated PI_for_EP and quality perception higher than consumers who disliked discount stores. When the HQLP appeal was presented, their preferences did not influence the evaluations. Accordingly, reaction to the HQLP appeal is not affected by consumers' preferences of store type, and this context-free feature may be considered as a benefit of the HQLP appeal.

\section{Conclusions}

Many consumers are drawn toward high quality and low price products. Therefore, consumers are likely to seek HQLP appeals to readily find such products, and retailers use such appeals to attract those consumers. Despite the widespread use of HQLP appeals in retailers' advertisements, scholarly research investigating consumers' responses to these appeals has been sparse. The current study extends that of Shirai [3], an exceptional study on these appeals, to cultivate a deeper understating regarding the effects of HQLP appeals on consumer evaluations. We compared the HQLP appeal with HQ-only and LP-only appeals across two store types having different price images. Our findings suggest that the retailer context strongly influences EP, WTP, and quality perception, and the appeal type strongly influences EP, quality perception, and PI_for_EP. The impacts of retailer context are larger than appeal type. Also, a strong interactive effect of appeal type and retailer context was observed for EP. For both stores, the HQ-only appeal had the highest EP and the HQLP and LP-only appeals came second. However, the effect of this appeal type was stronger for the department store than the discount store. In comparison of EP with WTP, for an expensive store, the HQLP appeal generated EP close to WTP. This produced higher purchase intention for the indicated EP, but lower quality perception. For the inexpensive store, the HQLP appeal generated EP lower than WTP. This produced higher purchase intention for the EP and higher quality perception. In sum, the HQLP appeal seems to be efficient for both stores, but works better for an inexpensive 
store.

The HQ-only appeal should be adopted with caution as it can generate consumer perceptions of high prices. Particularly, when used by retailers with an exclusive, luxury store, if the EP exceeds the consumer's level of WTP, then the consumer's desire to shop at that store may be decreased. Also, the LP-only appeal should be adopted with caution as it can generate lower quality perceptions when used by retailers with a low price image.

Whether to appeal to high quality or low price only, or both, seems to be a very important decision for marketers. They should select contextual appeals used in their advertisements with caution as consumers pay attention to them and use them in evaluations. In particular, quality and price appeals are influential to consumers. Upon determining an appropriate appeal, marketers should take account of consumer's store image, as this will impact on the effectiveness of the campaign. In addition, marketers realize that the characteristics of two IRPs, EP and WTP, are quite different. EP is influenced by contextual appeal and retailer context more than WTP. WTP is likely to influence consumers' purchase decisions more than EP. Therefore, examining IRP levels and whether they are separated widely may be necessary. At the same time, finding factors that influence WTP may also be necessary.

There are several limitations to this research. First, it would be interesting to investigate the cumulative effects of the HQLP appeal over time. If retailers adopt this appeal consistently over a period of time, then consumers' responses might be changed. Expert consumers are known to process information differently [36]. Therefore, knowledgeable consumers may have different attitudes toward the HQLP appeal. A comparative analysis between high-knowledge and low-knowledge consumers may produce new findings. Second, our subject pool consisted of a homogeneous student sample. Although we selected a product category after carefully considering the participants of our studies, the fact remains that shopping experiences, income levels, and interests differ. Analyses including adult and fully employed members of society are needed to confirm the general applicability of our findings. Finally, further research is necessary to examine actual purchasing behavior. The present study design does not replicate the real world in all aspects; therefore, field experiments are necessary to confirm the results.

\section{References}

[1] Rao, A.R. and Monroe, K.B. (1988) The Moderating Effect of Prior Knowledge on Cue Utilization in Product Evaluations. Journal of Consumer Research, 15, 253-264. http://dx.doi.org/10.1086/209162

[2] Wheatley, J.J. and Chiu, J.S.Y. (1977) The Effects of Price, Store Image, and Product and Respondent Characteristics on Perceptions of Quality. Journal of Marketing Research, 14, 181-186. http://dx.doi.org/10.2307/3150467

[3] Shirai, M. (2014) Impact of “High Quality, Low Price” Appeal on Consumer Evaluations. Working Paper \#317, Faculty of Business Administration, Yokohama National University, Yokohama.

[4] Bolton, L.E., Warlop, L. and Alba, J.W. (2003) Consumer Perceptions of Price (Un)Fairness. Journal of Consumer Research, 29, 474-491. http://dx.doi.org/10.1086/346244

[5] Thaler, R. (1985) Mental Accounting and Consumer Choice. Marketing Science, 4, 199-214. http://dx.doi.org/10.1287/mksc.4.3.199

[6] Kalyanaram, G. and Winer, R.S. (1995) Empirical Generalizations from Reference Price Research. Marketing Science, 14, Part 2 of 2, G161-G169.

[7] Mazumdar, T., Raj, S.P. and Shinha, I. (2005) Reference Price Research: Review and Propositions. Journal of Marketing, 69, 84-102. http://dx.doi.org/10.1509/jmkg.2005.69.4.84

[8] Garbarino, E. and Slonim, R. (2003) Determinants and Effects of Distinct Internal Reference Prices on Perceptions and Demand. Psychology \& Marketing, 20, 227-249. http://dx.doi.org/10.1002/mar.10069

[9] Klein, N.M. and Oglethorpe, J.E. (1987) Cognitive Reference Points in Consumer Decision Making. Advances in Consumer Research, 14, 183-187.

[10] Lowengart, O. (2002) Reference Price Conceptualization: An Integrative Framework of Analysis. Journal of Marketing Management, 18, 145-171. http://dx.doi.org/10.1362/0267257022775972

[11] Shirai, M. (2003) An Analysis of Multi-Dimensional Internal Reference Prices. Advances in Consumer Research, 30, 258-263.

[12] Kalwani, M.U., Yim, C.K., Rinne, H.J. and Sugita, Y. (1990) A Price Expectations Model of Customer Brand Choice. Journal of Marketing Research, 27, 251-262. http://dx.doi.org/10.2307/3172584

[13] Krishnamurthi, L., Mazumdar, T. and Raj, S.P. (1992) Asymmetric Response to Price in Consumer Brand Choice and 
Purchase Quantity Decisions. Journal of Consumer Research, 19, 387-400. http://dx.doi.org/10.1086/209309

[14] Lattin, J.M. and Bucklin, R.E. (1989) Reference Effects of Price and Promotion on Brand Choice Behavior. Journal of Marketing Research, 26, 299-310. http://dx.doi.org/10.2307/3172902

[15] Dickson, P.R. and Sawyer, A.G. (1990) The Price Knowledge and Search of Supermarket Shoppers. Journal of Marketing, 54, 42-53. http://dx.doi.org/10.2307/1251815

[16] Diamond, W.D. and Campbell, L. (1989) The Framing of Sales Promotions: Effects on Reference Price Change. Advances in Consumer Research, 16, 241-247.

[17] Kalwani, M.U. and Yim, C.K. (1992) Consumer Price and Promotion Expectations: An Experimental Study. Journal of Marketing Research, 29, 90-100. http://dx.doi.org/10.2307/3172495

[18] Krishna, A. and Johar, G.V. (1996) Consumer Perceptions of Deals: Biasing Effects of Varying Deal Prices. Journal of Experimental Psychology: Applied, 2, 187-206. http://dx.doi.org/10.1037/1076-898X.2.3.187

[19] Shirai, M. (2005) The Relationship between Internal Reference Price and Three Aspects of Dealing Patterns: Frequency, Depth, and Depth Variation. Asia Pacific Advances in Consumer Research, 6, 299-302.

[20] Folkes, V. and Wheat, R.D. (1995) Consumers' Price Perceptions of Promoted Products. Journal of Retailing, 71, 317328. http://dx.doi.org/10.1016/0022-4359(95)90028-4

[21] Raghubir, P. (1998) Coupon Value: A Signal for Price? Journal of Marketing Research, 35, 316-324. http://dx.doi.org/10.2307/3152030

[22] Compeau, L.D. and Grewal, D. (1998) Comparative Advertising: An Integrative Review. Journal of Public Policy and Marketing, 17, 257-273.

[23] Chandrashekaran, R. and Grewal, D. (2003) Assimilation of Advertised Reference Prices: The Moderating Role of Involvement. Journal of Retailing, 79, 53-62. http://dx.doi.org/10.1016/S0022-4359(03)00002-2

[24] Koppalle, P. and Lindsey-Mullikin, J. (2003) The Impact of External Reference on Consumer Price Expectations. Journal of Retailing, 79, 225-236. http://dx.doi.org/10.1016/j.jretai.2003.09.002

[25] Suter, T.A. and Burton, S. (1996) Believability and Consumer Perceptions of Implausible Reference Prices in Retail Advertisements. Psychology and Marketing, 13, 37-54. http://dx.doi.org/10.1002/(SICI)1520-6793(199601)13:1<37::AID-MAR3>3.0.CO;2-Q

[26] Lichtenstein, D.R. and Bearden, W.O. (1989) Contextual Influence on Perceptions o Merchant-Supplied Reference Prices. Journal of Consumer Research, 16, 55-66. http://dx.doi.org/10.1086/209193

[27] Burton, S., Lichtenstein, D.R. and Herr, P.M. (1993) An Examination of the Effects of Information Consistency and Distinctiveness in a Reference-Price Advertisement Context. Journal of Applied Social Psychology, 23, 2074-2092. http://dx.doi.org/10.1111/j.1559-1816.1993.tb01080.x

[28] Lichtenstein, D.R., Burton, S. and Karson, E.J. (1991) The Effect of Semantic Cues on Consumer Perceptions of Reference Price Ads. Journal of Consumer Research, 18, 380-391. http://dx.doi.org/10.1086/209267

[29] Grewal, D., Monroe, K.B. and Krishnan, R. (1998) The Effects of Price-Comparison Advertising on Buyers’ Perceptions of Acquisition Value, Transaction Value, and Behavioral Intentions. Journal of Marketing, 62, 46-59. http://dx.doi.org/10.2307/1252160

[30] Homburg, C., Koschate, N. and Hoyer, W.D. (2005) Do Satisfied Consumers Really Pay More? A Study of the Relationship between Customer Satisfaction and Willingness to Pay. Journal of Marketing, 69, 84-96. http://dx.doi.org/10.1509/jmkg.69.2.84.60760

[31] Krishna, A. (1991) Effect of Dealing Patters on Consumer Perceptions of Deal Frequency and Willingness to Pay. Journal of Marketing Research, 28, 441-451. http://dx.doi.org/10.2307/3172784

[32] Wertenbroch, K. and Skiera, B. (2002) Measuring Consumers' Willingness to Pay at the Point of Purchase. Journal of Marketing Research, 39, 228-241. http://dx.doi.org/10.1509/jmkr.39.2.228.19086

[33] Ranyard, R., Charlton, J.P., and Williamson, J. (2001) The Role of Internal Reference Prices in Consumers’ Willingness to Pay Judgments: Thaler's Bear Pricing Task Revisited. Acta Psychologica, 106, 265-283. http://dx.doi.org/10.1016/S0001-6918(00)00053-6

[34] Alba, J.W., Broniarczyk, S.M., Shimp, T.A. and Urbany, J.E. (1994) The Influence of Prior Beliefs, Frequency Cues, and Magnitude Cues on Consumer Perceptions of Comparative Price Data. Journal of Consumer Research, 21, 219235. http://dx.doi.org/10.1086/209394

[35] Bobinski Jr., G.S., Cox, D. and Cox, A. (1996) Retail “Sale” Advertising, Perceived Retailer Credibility, and Price Rationale. Journal of Retailing, 72, 291-306. http://dx.doi.org/10.1016/S0022-4359(96)90031-7

[36] Sujan, M. (1985) Consumer Knowledge: Effects on Evaluation Strategies Mediating Consumer Judgments. Journal of Consumer Research, 12, 31-46. http://dx.doi.org/10.1086/209033 
Scientific Research Publishing (SCIRP) is one of the largest Open Access journal publishers. It is currently publishing more than 200 open access, online, peer-reviewed journals covering a wide range of academic disciplines. SCIRP serves the worldwide academic communities and contributes to the progress and application of science with its publication.

Other selected journals from SCIRP are listed as below. Submit your manuscript to us via either submit@scirp.org or Online Submission Portal.
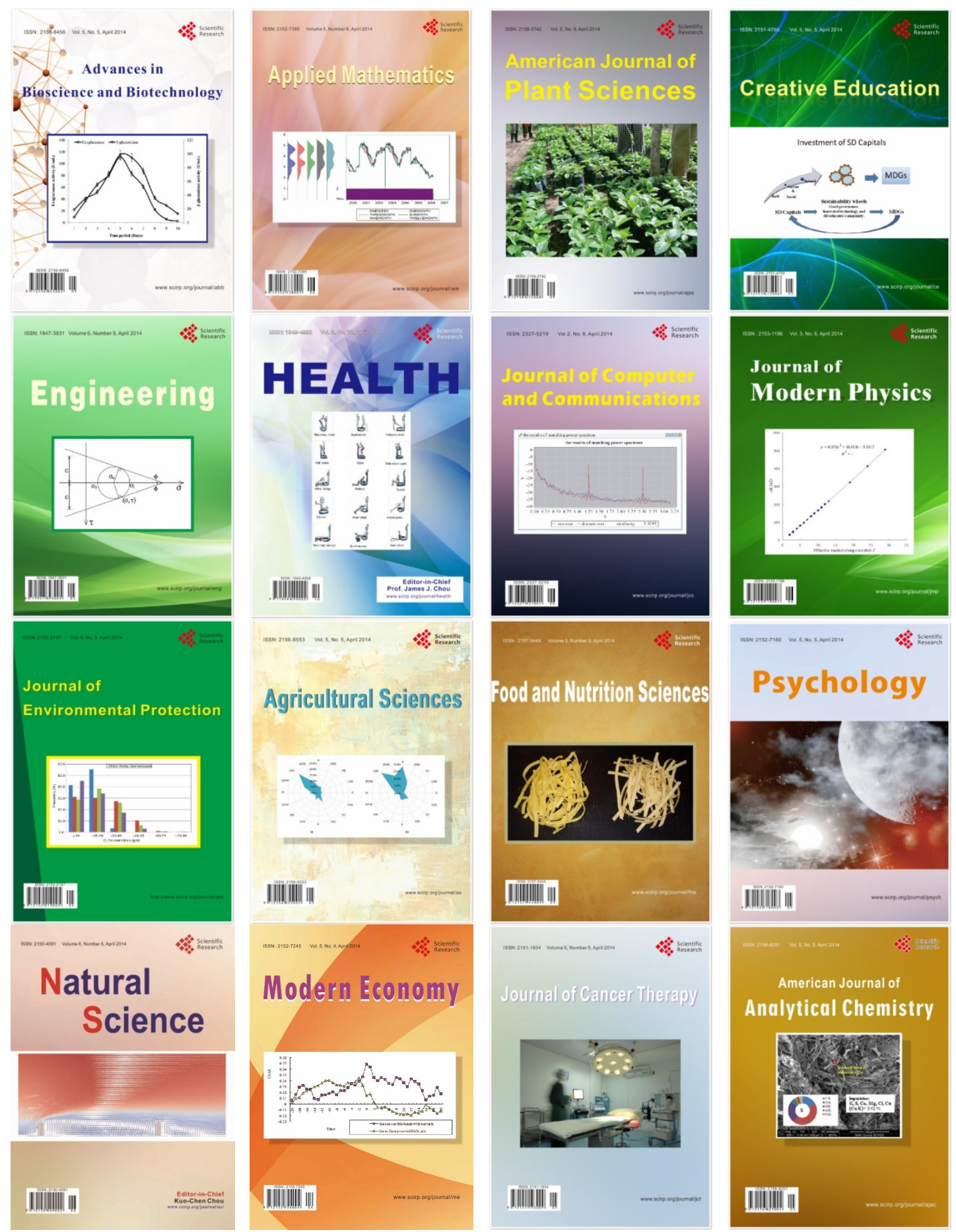